
\title{
R Research Soure \\ Fabrication of Multifunctionalized Graphene Oxide Doped Alginate Hybrid Spheres for Enhanced Fluoride Adsorption
}

\section{Antonysamy Jeyaseelan}

Anna University, University College of Engineering - Dindigul

Natrayasamy Viswanathan ( $\sim$ drnviswanathan@gmail.com )

Anna University, University College of Engineering - Dindigul https://orcid.org/0000-0003-4939-3442

\section{Research Article}

Keywords: Graphene oxide, AGO, Alginate, AGO@Alg spheres, Defluoridation, Field aptness, Recyclability.

Posted Date: July 23rd, 2021

DOl: https://doi.org/10.21203/rs.3.rs-735350/v1

License: (c) (1) This work is licensed under a Creative Commons Attribution 4.0 International License.

Read Full License 


\title{
Fabrication of Multifunctionalized Graphene Oxide Doped Alginate
}

\section{Hybrid Spheres for Enhanced Fluoride Adsorption}

\author{
Antonysamy Jeyaseelan, Natrayasamy Viswanathan* \\ Department of Chemistry, Anna University, University College of Engineering - Dindigul, \\ Dindigul - 624 622, Tamilnadu, India. \\ * Corresponding author. Tel.: +91-451-2554066 (O); fax: +91-451-2554066. \\ E-mail address: drnviswanathan@gmail.com (N. Viswanathan)
}

\begin{abstract}
In this present investigation, amine functionalized graphene oxide (AGO) doped on alginate (Alg) polymeric matrix gives AGO@Alg hybrid spheres was developed to explore its potential towards fluoride retention. The vital characterization techniques namely FTIR, TGA, SEM and XPS analysis of AGO@Alg hybrid spheres were acquired to identify its physicochemical properties. The liable parameters for fluoride adsorption onto AGO@Alg hybrid spheres were optimized in a batch mode to attain enhance defluoridation capacity (DC). The prepared AGO@Alg hybrid spheres follow the electrostatic interaction mechanism on defluoridation. The adsorption isotherms (Fruendlich, Langmuir, Temkin and DubininRadushkevich (D-R) models), kinetics (reaction and diffusion based models) and thermodynamic parameters $\left(\Delta \mathrm{S}^{\circ}, \Delta \mathrm{G}^{\circ}\right.$ and $\left.\Delta \mathrm{H}^{\circ}\right)$ were surveyed at 303,313 and $323 \mathrm{~K}$. To lessen the costeffectiveness of AGO@Alg hybrid spheres the recyclability test was conducted. The aptness of AGO@Alg hybrid spheres was also scrutinized for the fluoride contaminated field sample collected from fluoride endemic village.
\end{abstract}

Keywords: Graphene oxide; AGO; Alginate; AGO@Alg spheres; Defluoridation; Field aptness: Recyclability. 


\section{Introduction}

Fluoride is considered as vital micro-nutrient liable for the bone and dental mineralization. But excess fluoride in drinking water leads to the irremediable disease in human is described as fluorosis [1]. Therefore the tolerable limit of fluoride in drinking water is fixed as $1.5 \mathrm{mg} / \mathrm{L}$ as recommended by WHO [2]. Hence, the safeguarding of fluoride is the finest remedy. The frequently explored removal methods like biological process, ion-exchange, adsorption, reverse osmosis and precipitation [3-7] are researched with the environmental researchers towards defluoridation wherein adsorption method is the finest method due to its simplicity, easy operation and economical one [8].Recently several adsorbents material namely metal oxides, activated alumina, zeolite, polymeric material, activated carbon, clay materials, etc., [9-13] were reported towards fluoride removal and these materials have some limitations such as poor selectivity, low surface area and low adsorption capacity [14].

To overcome this difficulty, in this study carbon-based adsorbent material was utilized towards fluoride removal. The mother of carbon-based material is graphene which consist of carbon atoms with single layers attached collectively by covalent bonds $\left(\mathrm{sp}^{2}\right)$ [15]. It is portrayed as respective of graphite is made of numerous graphite layer held collectively with force of van der Waals attraction [16]. The majority of the graphene based materials have some promising properties such as high mechanical strength, high electron mobility, tunable optical properties, fast heterogeneous electron transfer rate and quantum hall effects build them to be utilized in assortment of various applications fields such as batteries, sensors, nano-electronics, sensors and super capacitors [17-20].

The exfoliation of graphene could be attained with intercalation, thermal expansion, reduction, chemical modification and oxidation [21]. Among the numerous techniques, graphite oxidation with strong oxidizing agents to form graphene oxide (GO) which is nonconductive 
hydrophilic carbon material has received huge attention owing to its easy synthetic method [22]. The introduction of functional groups such as ketone, epoxide, carboxylic acid and alcohol with disruption of aromatic lattice builds GO to be hydrophilic in nature using modified Hummers method for the graphene oxidation [23]. In addition, GO has some unique advantages like physical, chemical and mechanical properties [24]. However, GO possess poor selectivity and low adsorption capacity towards fluoride adsorption [25].

To enhance the adsorption property of GO material, amine functionalized GO based materials was developed towards fluoride removal. Recently, amine functionalized GO based materials towards toxic ion removal and other potential applications [26-27]. However, the powder form of amine functionalized GO materials has some limitations such as powder form which create pressure drop during filtration [28]. To prevail over these problems, biopolymer encapsulated AGO material was developed towards fluoride removal [29].Currently, enhanced usage of biopolymers and biomaterials for adsorption system has received more consideration owing to their abundance, eco-friendly, bio-functional, low cost and biocompatible nature [3031]. One of the biopolymer is alginate (Alg) which has capable cross-linking talent with functional groups and explored for various pollutant removal from aquatic environment [32]. In addition, the structurally modified AGO favor to equivalently disperse into Alg poly-matrix which gives easily separable biohybrid spheres namely AGO@Alg hybrid spheres for enhanced fluoride removal.

Hence, the present investigation AGO@Alg hybrid spheres was prepared and practically employed towards adsorption of fluoride from aqueous medium. The fluoride adsorption onto AGO@Alg hybrid spheres, the liable parameters was investigated in batch mode to attain the enhanced DC. The nature, feasibility and order of the fluoride adsorption onto AGO@Alg hybrid spheres were explored by adsorption isotherms, thermodynamic parameters and adsorption 
kinetic models. The mechanism of fluoride adsorption onto AGO@Alg spheres was also elucidated. To verify the cost-effectiveness and industry applicable stage of AGO@Alg hybrid spheres was too scrutinized.

\section{Experimental section}

\subsection{Materials}

Sodium fluoride $(\mathrm{NaF})$, potassium permanganate $\left(\mathrm{KMnO}_{4}\right)$, ethanol $\left(\mathrm{CH}_{3} \mathrm{CH}_{2} \mathrm{OH}\right)$, sodium chloride $(\mathrm{NaCl})$, hydrogen peroxide $\left(\mathrm{H}_{2} \mathrm{O}_{2}\right)$, sodium nitrate $\left(\mathrm{NaNO}_{3}\right)$, sodium alginate (Alg), calcium chloride $\left(\mathrm{CaCl}_{2}\right)$, ethylenediamine (EDA), graphite powder, sulphuric acid $\left(\mathrm{H}_{2} \mathrm{SO}_{4}\right)$, potassium sulphate, sodium bicarbonate, N,N-dimethylformamide (DMF) were supplied from Merck, India.

\subsection{Synthesis of AGO@Alg spheres}

GO was prepared by modified Hummer's method [33]. AGO was prepared using EDA using standard procedure [34]. To prepare AGO@Alg spheres, Alg (2 g) was completely dissolved in deionized water $(100 \mathrm{~mL})$. Then, $0.1 \mathrm{~g}$ of the prepared AGO material was slightly dispersed with deionized water. Further, the AGO solution was added into Alg solution. The mixture of solution was strongly stirring by using the magnetic stirrer for $2 \mathrm{~h}$ to attain the uniform AGO@Alg biocomposite solution. After that, AGO@Alg biocomposite solution was gradually dropped into $2 \% \mathrm{CaCl}_{2}(50 \mathrm{~mL})$ solution to obtain an exploitable AGO@Alg hybrid spheres. The obtained AGO@Alg spheres were kept in the mother liquor upto $24 \mathrm{~h}$ for intensification purpose [35]. Lastly, AGO@Alg spheres were filtered and it was dried out in hot air oven at $80^{\circ} \mathrm{C}$ upto $2 \mathrm{~h}$ for defluoridation studies. The schematic diagram of the synthesis of AGO@Alg hybrid spheres was portrayed in Figure 1. 


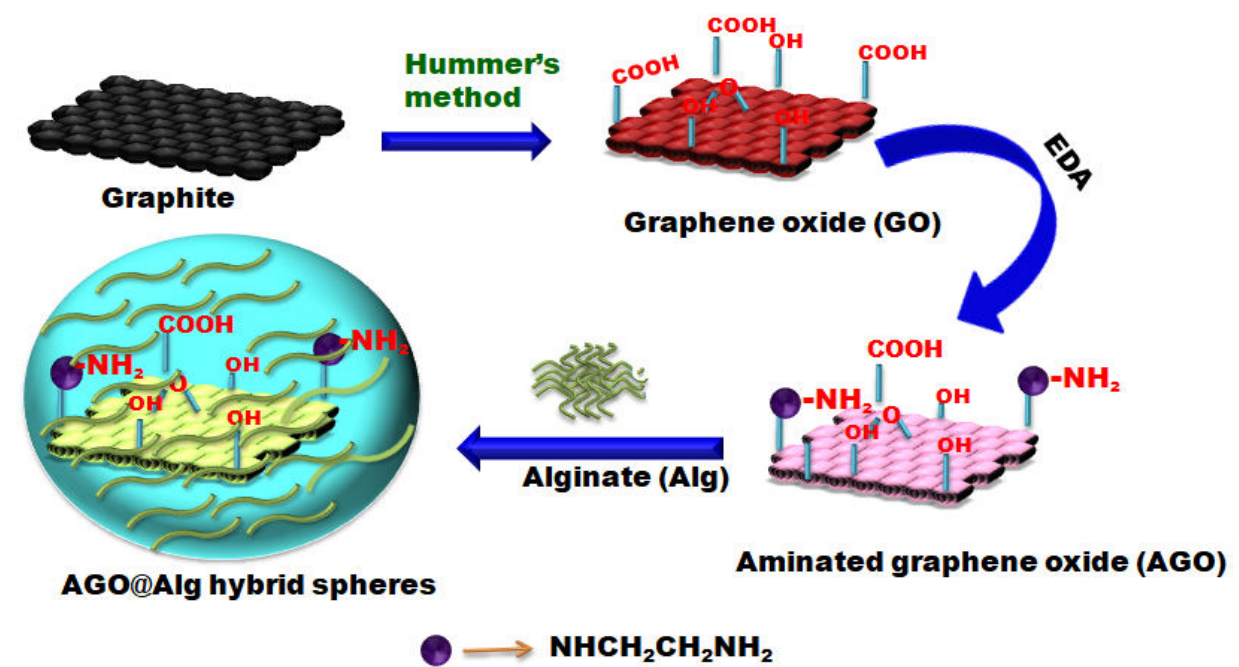

Figure 1. Graphical diagram of the synthesis of AGO@Alg hybrid spheres.

\subsection{Fluoride adsorptive experiments}

The prepared AGO@Alg spheres were poured with $50 \mathrm{ml}$ of initial fluoride solution (10 $\mathrm{mg} / \mathrm{L}$ ) was taken into $250 \mathrm{~mL}$ iodine flask and it was shaken with thermo mechanical shaker in the ranges from 10-60 min. Further, the equilibrium concentration was analyzed by fluoride ion selective electrode. The adsorbate $\mathrm{pH}$ concentration of 3 to 11 was modified with addition of 0.1 mole of $\mathrm{HCl} / \mathrm{NaOH}$. The kinetics and isotherms studies towards fluoride adsorption was conducted with taking different initial adsorbate solution of $8,10,12$ and $14 \mathrm{mg} / \mathrm{L}$ at altered temperatures at 303,313 and $323 \mathrm{~K}$. The defluoridation capacity (DC) was calculated by following equation (1),

$$
\text { Defluorida tion capacity (DC) }=\frac{\mathrm{C}_{\mathrm{i}}-C_{e}}{m} V X 1000 \mathrm{mgF}^{-} \mathrm{kg}^{-1}
$$

where $\mathrm{C}_{\mathrm{i}}$ is the initial fluoride concentration $(\mathrm{mg} / \mathrm{L}), \mathrm{C}_{\mathrm{e}}$ is the final fluoride concentration $(\mathrm{mg} / \mathrm{L})$, $\mathrm{V}$ is the adsorbate volume ( $\mathrm{L}$ ) and $\mathrm{m}$ is the amount of adsorbent dosage $(\mathrm{g})$. 


\subsection{Adsorbent characterization}

The presence of functional composition of AGO@Alg hybrid spheres were recognized by Fourier transform infrared (FTIR) [model: JASCO-460 plus). Thermogravimetric (TG) analysis (model: Universal V4.5A TA) was performed to detect the thermal stability of GO, AGO and AGO@Alg spheres. The morphological image of AGO@Alg hybrid spheres with fluoride adsorption was scrutinized by scanning electron microscope (SEM) (Model: Vega3 Tescan). The binding state of the elements present in AGO@Alg spheres and fluoride adsorbed AGO@Alg spheres was studied by X-ray Photoelectron Spectroscopy (XPS) [PHI - VERSAPROBE III].

\subsection{Analysis}

The fluoride concentration was find using Thermo Orion Benchtop multiparameter kit (model: VERSA STAR92) with fluoride ion selective electrode [36]. The solution pH from 3 to 11 was tuned by $\mathrm{pH}$ electrode with Thermo Orion Benchtop multiparameter kit (model: VERSA STAR92). The $\mathrm{pH}_{\mathrm{zpc}}$ ( $\mathrm{pH}$ at zero point charge) of AGO@Alg hybrid spheres was analyzed by pH drift technique. The water quality responsible parameters viz., total hardness, dissolved oxygen, total dissolved solids, chloride and temporary hardness were evaluated by standard protocol.

\subsection{Regeneration studies}

The investigation was made to assess the recyclable behavior of AGO@Alg hybrid spheres. Approximately $0.1 \mathrm{~g}$ of fluoride treated AGO@Alg spheres were decanted into $50 \mathrm{ml}$ of 0.1 M NaOH eluent. Further, the blended solution was magnetically stirred in mechanical shaker for the period of optimal time. Afterwards, AGO@Alg hybrid spheres were detached by centrifugation and after equilibrium fluoride concentration was evaluated using fluoride ion selective electrode. Afterward AGO@Alg hybrid spheres were sluiced with $\mathrm{HCl}(0.01 \mathrm{M})$ and after dehydrated in hot air oven, further it was recycled for fluoride adsorption experiments. This 
route was reiterated for numerous periods and finally the fluoride removal efficiency of AGO@Alg hybrid spheres was measured as following formula,

$$
\text { Removal efficiency }(\%)=\frac{\mathrm{C}_{\mathrm{i}}-C_{e}}{\mathrm{C}_{\mathrm{i}}} 100
$$

\subsection{Statistical tools}

The fitness of isotherm and kinetic models were verified by chi-square analysis $\left(\chi^{2}\right)$ standard deviation (sd) and correlation coefficient (r). Besides, all the experimental data towards defluoridation were determined using the Microcal Origin software (version 15).

\section{Results and discussion}

\subsection{Characterization studies of adsorbents}

\subsubsection{Functional groups investigation}

To aid the occurrence of chemical composition and chemical bond between- $\mathrm{NH}_{2}$ and GO was studied by FTIR analysis. FTIR spectra of Alg, AGO, GO, AGO@Alg spheres and fluoride adsorbed AGO@Alg spheres were depicted in Figure 2a and b. From the obtained results of FTIR, the sheet of GO have the carbonyl group $(\mathrm{C}=\mathrm{O})$ in the $\mathrm{COOH}$ was placed at end of edge corner (c.f. Figure 2a). The adsorption stretching vibration peaks of $\mathrm{C}=\mathrm{O}$ in the $\mathrm{COOH}$ was detected at 1724 and $1628 \mathrm{~cm}^{-1}$ [37]. In addition, adsorption of stretching -OH was attribute to the monitored broad band at $3452 \mathrm{~cm}^{-1}$ [38]. Moreover, the stretching vibration mode of other groups such as C-O was detected at $1400 \mathrm{~cm}^{-1}$ and $\mathrm{C}-\mathrm{H}$ was detected at 2938 and $2852 \mathrm{~cm}^{-1}$ [39]. Further, modification of amine groups (AGO); also the GO bands were detected at 1723 $\mathrm{cm}^{-1}$. Though, the other bands at 1628 and $1400 \mathrm{~cm}^{-1}$ roughly disappeared or subsided obviously and new band observed at $1580 \mathrm{~cm}^{-1}$ was improved attribute to the adsorption of $\mathrm{N}-\mathrm{H}$ stretching vibration in-plane and this was noticeably signify GO was efficiently functionalized with EDA [40] (c.f. Figure $2 \mathrm{a}$ and b). The comparative high intensity bands noted at $3300-3600 \mathrm{~cm}^{-1}$ and it 
was destabilized after functionalization of amine groups attribute to the $\mathrm{N}-\mathrm{H}$ stretching vibration in amine groups [41]. For Alg FTIR spectra, the $-\mathrm{OH}$ and $-\mathrm{COOH}$ groups stretching vibration bands were noted at 1629 and $3396 \mathrm{~cm}^{-1}$ respectively [42] (c.f. Figure 2b). After Alg incorporation with $\mathrm{AGO}$, the corresponding $\mathrm{AGO}$ and $\mathrm{Alg}$ peaks were reappeared in the AGO@Alg hybrid spheres which denote that Alg successfully incorporated with AGO (c.f. Figure 2b). For AGO@Alg hybrid spheres, the corresponding intensity peaks of N-H, OH and $\mathrm{COOH}$ were increased than AGO and Alg which signifies the good formation of AGO@Alg hybrid spheres [43]. In addition, the FTIR spectra of AGO@Alg hybrid spheres noted that no new peaks were observed compared to AGO and Alg, revealing that there was no chemical bond formed with addition of Alg. After fluoride adsorption, the corresponding peaks were increased may due to more fluoride ion occupies the adsorbent surface which signifies that fluoride ion efficiently attract with fluoride ion (c.f. Figure $2 b$ ).
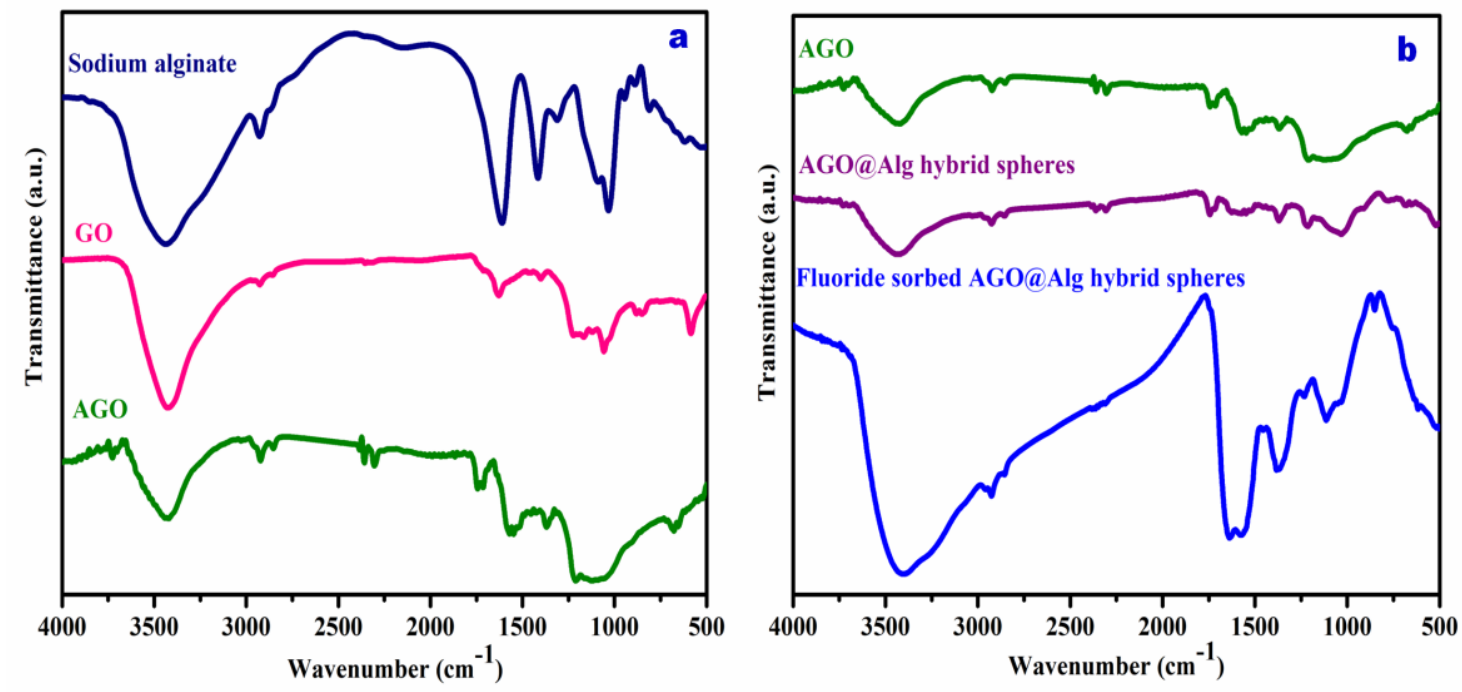

Figure 2. FTIR spectra of (a) sodium alginate, GO and AGO; (b) AGO@Alg hybrid spheres and fluoride sorbed AGO@Alg hybrid spheres. 


\subsubsection{Thermal stability investigation}

TGA analysis results of AGO and GO were depicted in Figure 3. The minor weight loss arisen close by $100{ }^{\circ} \mathrm{C}$ is owing to loss of water. Then, the foremost weight loss noted in the region of $180^{\circ} \mathrm{C}$ is attributed to weight loss of labile oxygen functional groups [44]. After, again, the thermal stability of GO was increases after functionalization of amine groups [45]. The maximum decomposition of amine groups were noted at $358^{\circ} \mathrm{C}$ for AGO was shown in Figure 3. Moreover, the encapsulation of Alg with AGO, the primary decomposition temperature of AGO@Alg hybrid spheres started to reduce, because particles start to aggregate once they have exceeded the vital level of loading. Hence, these results recommend that the AGO improve the thermal stability of AGO@Alg hybrid spheres.

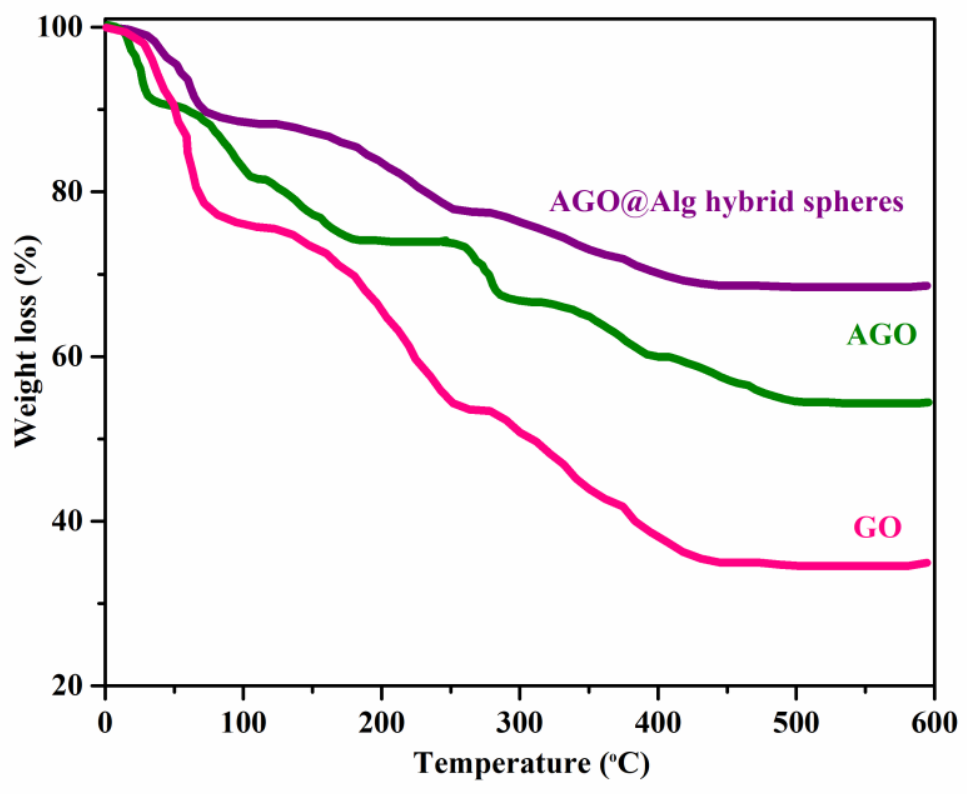

Figure 3. TGA spectra of GO, AGO and AGO@Alg hybrid spheres.

\subsubsection{Surface morphology analysis}

The surface morphological study of the prepared adsorbent material was evaluated by SEM analysis (c.f. Figure 4). Digital and dried image of AGO@CS hybrid spheres was depicted in Figure 4a and b. SEM micrographs of GO expose that the "sponge cake" shapes on account of 
stack structure of the GO sheets. After functionalized with amine, the AGO contain porous nature of randomly aggregated thin sheets forms and disordered framework because of amine groups are functionalized with GO sheet which demonstrated AGO was successfully synthesized. Further AGO encapsulated with Alg (AGO@Alg hybrid spheres), the surface was structurally modified due to Alg encapsulation with AGO (c.f. Figure 4c). After fluoride adsorption, the morphology of AGO@Alg hybrid spheres was altered owing to fluoride ion occupies the pores of AGO@Alg hybrid spheres (c.f. Figure 4d).
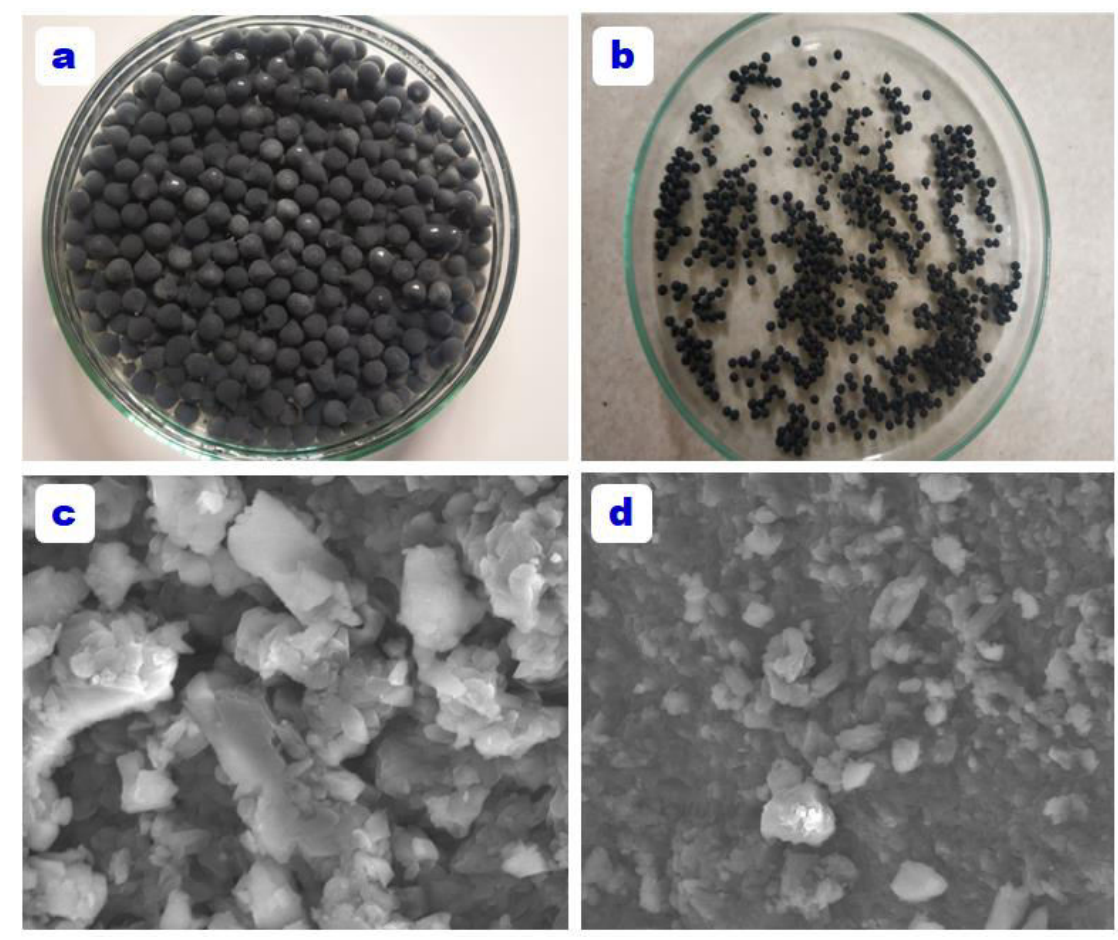

Figure 4. Digital image of (a) AGO@Alg hybrid spheres, (b) dried AGO@Alg hybrid spheres, SEM micro-graphs of (c) AGO@Alg hybrid spheres at $10 \mu \mathrm{m}$ and (d) fluoride adsorbed AGO@Alg hybrid spheres at $10 \mu \mathrm{m}$.

\subsubsection{XPS studies}

XPS is a very helpful technique for investigate the composition of the functional groups present in the adsorbents. The occurrence of all the composition of functional groups in AGO was explored semi-quantitatively using concluded the valance state and binding energies 
changes. The XPS wide scan spectra result of AGO@Alg spheres and fluoride adsorbed AGO@Alg spheres were depicted in Figure 5. The attribute peaks of O1s, N1s, and C1s were experimentally noted at 533, 399, and $285 \mathrm{eV}$. This obviously exhibit that after functionalized amine with GO, the intensity peak of $\mathrm{N} 1 \mathrm{~s}$ was increased. This results demonstrated that after functionalized amine with GO the atomic percentage of the $\mathrm{N}$ in the adsorbents was improved from the GO of zero to AGO of $12.5 \%$ as well as the atomic ratio of N/C increases to 0.169 which clearly point out the amine functionalized route successfully makes $\mathrm{N}-\mathrm{H}$ groups onto the surface of GO [46]. This surveillance is finely reliable by FTIR spectra results. The ascribe peaks of GO was attribute to the C1s spectrum typically noted at $284.8,286.6,287.1$, and $287.6 \mathrm{eV}$ which was attributed to GO was well fitted with corresponding peaks of $\mathrm{sp}^{2}$ hybridized $\mathrm{C}$ atoms, $\mathrm{C}-\mathrm{OH}, \mathrm{C}-\mathrm{O}$ (epoxy/ether) groups, and $\mathrm{C}=\mathrm{O}$ (carbonyl/carboxyl), respectively. In addition, the extra constituent peak was observed at $285.8 \mathrm{eV}$ in $\mathrm{C} 1 \mathrm{~s}$ spectrum of AGO which was attributed to the $\mathrm{C}-\mathrm{N}$ groups. Significantly, the intensity peaks of oxygen concentration was diminished were observed. In addition, the intensity peaks of $\mathrm{C} 1 \mathrm{~s}$ was diminished were observed at 286.6 to $288.0 \mathrm{eV}$ [47]. From Figure 5, the attributed spectrum of $\mathrm{N} 1 \mathrm{~s}$ of $\mathrm{NH}_{2}-\mathrm{GO}$ could be deconvoluted into two peaks with B.E. of 398.7 and $399.8 \mathrm{eV}$ were allocated to CO-NH (pyridinic) and $\mathrm{C}-\mathrm{NH}_{2}$ (primary amine) individually which demonstrates the ethylenediamine was reacted with oxygen group of graphene oxide. 


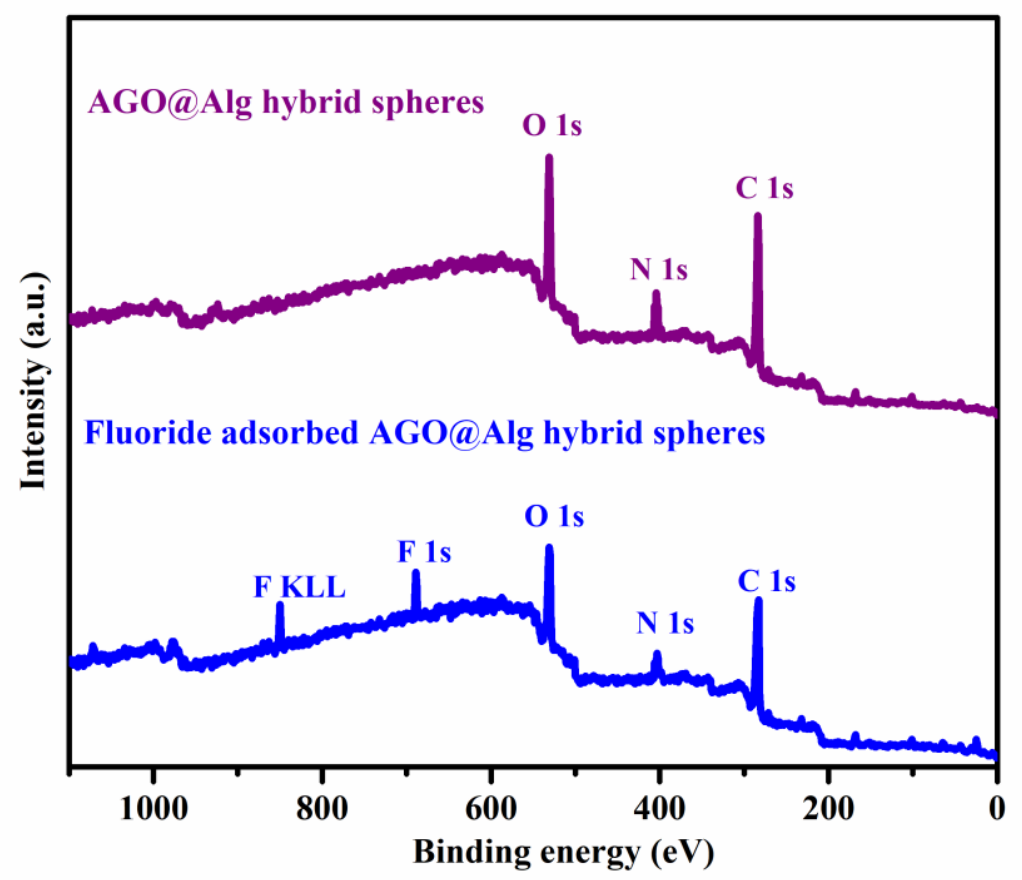

Figure 5. XPS spectra of AGO@Alg hybrid spheres and fluoride adsorbed AGO@Alg hybrid spheres.

Further, Alg encapsulation with AGO, the corresponding peaks such as $\mathrm{C}, \mathrm{N}$ and $\mathrm{O}$ was reappeared in AGO@Alg hybrid spheres with slightly variation of intensity peaks which may due to Alg encapsulation with AGO [48]. Afterwards, for fluoride treated in AGO@Alg hybrid spheres, the corresponding peaks such as $\mathrm{C}, \mathrm{N}$ and $\mathrm{O}$ was also reappeared in fluoride adsorbed AGO@Alg hybrid spheres with new peaks of fluoride which indicates fluoride adsorption was confirmed onto AGO@Alg hybrid spheres. After defluoridation, the intensity peaks were reduced owing to fluoride adsorption happened onto the AGO@Alg hybrid spheres.

\subsection{Influence of agitation time}

During the contact time studies, the DCs of GO, AGO and AGO@Alg spheres was performed at varied adsorption time ranges from 10 to $60 \mathrm{~min}$. The contact time results shows that the GO, AGO and AGO@Alg hybrid spheres have the superior DCs of 2450, 4001 and 4440 $\mathrm{mgF}^{-} \mathrm{kg}^{-1}$ at 50, 40 and 30 min respectively, while the GO and AGO developed in this 
investigation have smaller DC and attained the saturation point arrived at 50 and 40 min of contact time respectively (Figure 6a). Since, it was assumed that AGO@Alg hybrid spheres utilized for residual fluoride adsorption studies by preferred $30 \mathrm{~min}$ of equilibrium time.

\subsection{Effect of AGO@Alg hybrid spheres dosage}

In this dosage test, AGO@Alg dosage was used in the range of $0.05-0.25 \mathrm{~g}$. From the observed results, at initial stage the DCs of AGO@Alg hybrid spheres were enhanced from 0.05 to $0.1 \mathrm{~g}$, achieve utmost at $0.1 \mathrm{~g}$ and after $0.1 \mathrm{~g}$ of AGO@Alg spheres was adsorption ability slowed down (Figure 6b). However, AGO@Alg hybrid spheres dosage raises, the DCs was too enhanced upto $0.1 \mathrm{~g}$ of dosage and then get diminished. The higher dosage ranges above $0.1 \mathrm{~g}$, the binding sites of AGO@Alg spheres and the accessibility higher than initial fluoride solution thus DC was diminished. Therefore, $0.1 \mathrm{~g}$ of AGO@Alg spheres dosage was selected as optimized dosage for further defluoridation experiments.

\subsection{Impact of initial fluoride concentration}

The initial fluoride solution was preferred as 2, 4, 6, 8, 10, 12 and $14 \mathrm{mg} / \mathrm{L}$ which subsequently separately soaked with 0.1 g of AGO@Alg spheres. The DC of AGO@Alg hybrid spheres were progressively improved as initial fluoride solution was greater and achieves equilibrium (Figure 6c). At greater fluoride solution, the strong of mass transfer was 

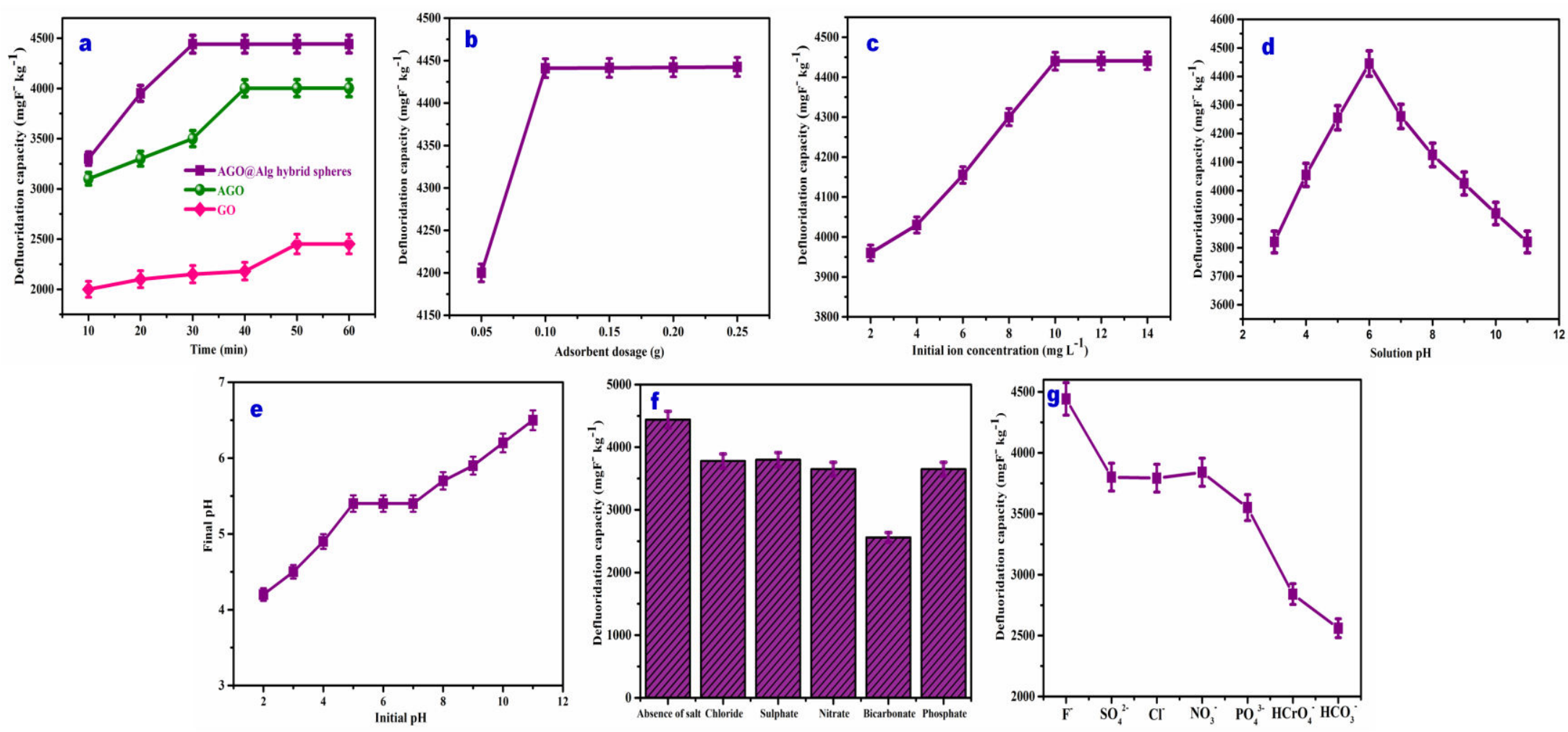

Figure 6. (a) Influence of contact time of GO, AGO and AGO@Alg hybrid spheres on the fluoride adsorption, effect of (b) AGO@Alg hybrid spheres dosage, (c) initial fluoride concentration, (d) solution $\mathrm{pH}$, (e) $\mathrm{pH}_{\mathrm{zpc}}$ analysis, (f) co-ions and (g) selectivity study of AGO@Alg hybrid spheres on the fluoride adsorption. 
triumph over with transportable force at AGO@Alg hybrid spheres/fluoride surface consequently $\mathrm{DC}$ rises at $10 \mathrm{mg} / \mathrm{L}$ of fluoride concentration. Hence, the best initial fluoride solution was chosen as $10 \mathrm{mg} / \mathrm{L}$ for remaining fluoride removal studies.

\subsection{Adsorbate pH}

The acidic and basic condition of adsorbate solution not only modifies the surface possibilities of the AGO@Alg hybrid spheres adsorbent then similarly modifies the assembly of ions. From Figure 6d the DC sloped with rises of adsorbate $\mathrm{pH}$ from 3 to 6 , suggesting that $\mathrm{pH}=6$ was the optimized state for fluoride adsorption onto AGO@Alg hybrid spheres. From Figure 6d, the DC descended with raises of $\mathrm{pH}$ from 3-6, suggesting the $\mathrm{pH}=6$ was the optimized condition for fluoride adsorption on AGO@Alg hybrid spheres. The $\mathrm{pH}$ at zero point charge $\left(\mathrm{pH}_{\text {zpc }}\right)$ analysis was obtained to be 5.32. The electrostatic interaction mechanism is one of the defluoridation mechanism which find made by the attraction of positive charge of the AGO@Alg hybrid spheres with fluoride ion [49].

The observed result of $\mathrm{pH}_{\mathrm{zpc}}$ analysis demonstrates that at $\mathrm{pH}<\mathrm{pH}_{\mathrm{zpc}}$, the AGO@Alg hybrid spheres surface entirely protonated (c.f. Figure 6e). The protonated surface of AGO@Alg hybrid spheres was adsorbed by fluoride ion via electrostatic attraction. In disagreement, at $\mathrm{pH}$ $>\mathrm{pH}_{\mathrm{zpc}}$ the AGO@Alg hybrid spheres surface was fully occupied by $\mathrm{OH}^{-}$ions instead of fluoride ion. Furthermore, the solution of $\mathrm{pH}$ medium was achieves $\mathrm{pH}=7$ after defluoridation which state the suitability of AGO@ Alg spheres at diverse pH environment.

\subsection{Co-ions and selectivity studies}

Mostly potable water comprises multiplicity of interfering anions, these interfering anions may influence the fluoride adsorption by AGO@Alg hybrid spheres. The obtained results of Figure 6f noticeably signifies the somewhat influence of AGO@Alg hybrid spheres in the occurrence of other challengers ions viz., $\mathrm{SO}_{4}{ }^{2-}, \mathrm{NO}_{3}{ }^{-}, \mathrm{HCO}_{3}{ }^{-}, \mathrm{HCrO}_{4}{ }^{-}, \mathrm{Cl}^{-}$and $\mathrm{PO}_{4}{ }^{3-}$ in aqueous 
medium. The declared challenger's ions have the diverse undesirable effects. Unexpectedly, the DC was drastically fallen when the $\mathrm{HCO}_{3}{ }^{-}$ion was engaged onto the active sites of the AGO@Alg hybrid spheres. The first reason could be comparable ionic size of $\mathrm{HCO}_{3}{ }^{-}$with $\mathrm{F}^{-}$ion and the second reason is the binding force attraction of $\mathrm{HCO}_{3}{ }^{-}$with $\mathrm{AGO} @ \mathrm{Alg}$ hybrid spheres was stronger than $\mathrm{SO}_{4}{ }^{2-}, \mathrm{NO}_{3}{ }^{-}, \mathrm{HCrO}_{4}{ }^{-}, \mathrm{Cl}^{-}$and $\mathrm{PO}_{4}{ }^{3-}[50]$. In addition, $\mathrm{SO}_{4}{ }^{2-}, \mathrm{PO}_{4}{ }^{3-}, \mathrm{HCrO}_{4}{ }^{-}, \mathrm{Cl}^{-}$ and $\mathrm{NO}_{3}{ }^{-}$too have the rivalry in existence on defluoridation.

Additionally, the selectivity studies of AGO@Alg hybrid spheres on defluoridation was examined and shown in Figure 6g. The attained results of AGO@Alg hybrid spheres have the boosted DCs to fluoride than the other adsorbates $\left(\mathrm{SO}_{4}{ }^{2-}, \mathrm{HCrO}_{4}{ }^{-}, \mathrm{HCO}_{3}{ }^{-}\right.$and $\left.\mathrm{Cl}^{-}\right)$. Therefore, the results indicate that the synthesized AGO@Alg hybrid spheres have tremendous selectivity nature for fluoride removal and it was practically applicable for fluoride removal studies.

\subsection{Isotherms studies}

The isotherms models of adsorption studies namely Langmuir [51], Freundlich [52], Dubinin-Radushkevich (D-R) [53] and Temkin [54] were employed to decide the optimum data of AGO@Alg hybrid spheres towards fluoride removal was conducted by chosen of varied initial fluoride solutions viz., 8, 10, 12 and $14 \mathrm{mg} / \mathrm{L}$ and varied temperature viz., 303, 313 and $323 \mathrm{~K}$. The $n$ values of Fruendlich isotherm $>1$ and $0<1 / n<1$ condition the relevant of Freundlich isotherm. The stronger interaction of AGO, AGO@Alg and AGO@CS onto fluoride adsorption was stated by Freundlich isotherm and its $n$ value $>1$ and $0<1 / n<1$ state the suitability of Freundlich isotherm. The measured value of $\mathrm{Q}^{\mathrm{o}}(\mathrm{mg} / \mathrm{g})$ in Langmuir isotherm was receiving improved with raises of temperature through defluoridation process.

Additionally, the $\mathrm{R}_{\mathrm{L}}$ value of Langmuir isotherm was obtained from 0 to 1 reveals the feasible nature of defluoridation by AGO@Alg hybrid spheres. The E values of D-R from 7 to 9 $\mathrm{kJ} / \mathrm{mol}$ denotes fluoride adsorption was physisorption nature while the $\mathrm{E}$ values above $10 \mathrm{~kJ} / \mathrm{mol}$ 
the signify fluoride adsorption was chemisorptions nature [55]. The $\mathrm{K}_{\mathrm{T}}$ and $\mathrm{B}_{1}$ isotherm constants were attained from the linear plot of $\mathrm{q}_{\mathrm{e}} \mathrm{vs} \ln \mathrm{C}_{\mathrm{e}}$ (Temkin plots) which was used to find the chemical adsorption of the fluoride onto the surface of AGO@Alg hybrid spheres. In addition the attained values of $\mathrm{E}$ above $9 \mathrm{~kJ} / \mathrm{mol}$ denote the interaction of $\mathrm{AGO} @ \mathrm{Alg}$ hybrid spheres to fluoride adsorption was identified to be chemisorption nature. The attained isotherm result of AGO@Alg hybrid spheres towards fluoride adsorption was declared that the Langmuir (monolayer adsorption) isotherm more applicable model than Temkin, D-R and Freundlich isotherm model owing to lower values of sd and $\chi^{2}$ with greater $r$ value respectively (c.f. Table 1).

\subsection{Thermodynamic parameters studies}

Thermodynamic parameters namely standard enthalpy change $\left(\Delta \mathrm{H}^{\circ}\right)$, standard entropy change $\left(\Delta \mathrm{S}^{\circ}\right)$ and Gibbs free energy change $\left(\Delta \mathrm{G}^{\circ}\right)$ was determined by Khan and Singh strategy [56]. The values of $\Delta \mathrm{G}^{\circ}<0$ and $\Delta \mathrm{H}^{\circ}>0$ indicate spontaneity and endothermic nature of fluoride adsorption. In this investigation, the obtained value of $\Delta \mathrm{G}^{\circ}<0$ indicates the fluoride adsorption of AGO@Alg hybrid spheres was spontaneity nature. During adsorption, the obtained experimental values of $\Delta \mathrm{H}^{\circ}$ is positive noticeably reveals that enthalpy is absorbed between AGO@Alg hybrid spheres and fluoride [57]. In addition, the enhancement of $\mathrm{DCs}\left(\mathrm{Q}^{\circ}\right)$ at monolayer coverage with raising temperature represents the endothermic nature of fluoride adsorption by AGO@Alg hybrid spheres (c.f. Table 1). Moreover, the attained $\Delta \mathrm{H}^{\circ}$ values below than $40 \mathrm{~kJ} / \mathrm{mol}$ states the defluoridation by AGO@Alg hybrid spheres was chemical adsorption nature. Additionally, the obtained values of $\Delta \mathrm{S}^{\circ}$ was around zero which demonstrates randomness was occurred almost nil after fluoride adsorption due to no further driving force particle was arisen but they stick onto the AGO@Alg hybrid spheres surface. 
Table 1. Adsorption isotherm and thermodynamic studies of AGO@Alg hybrid spheres for fluoride removal.

\begin{tabular}{|c|c|c|c|c|}
\hline $\begin{array}{l}\text { Isotherms \& } \\
\text { thermodynamic } \\
\text { parameters }\end{array}$ & Values & $303 \mathrm{~K}$ & $313 \mathrm{~K}$ & $323 \mathrm{~K}$ \\
\hline \multirow{6}{*}{ Freundlich } & $1 / \mathrm{n}$ & 0.786 & 0.789 & 0.793 \\
\hline & $\mathrm{n}$ & 8.093 & 8.097 & 8.103 \\
\hline & 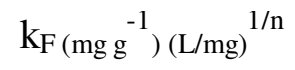 & 4.256 & 4.258 & 4.263 \\
\hline & $\mathrm{r}$ & 0.980 & 0.983 & 0.987 \\
\hline & sd & 0.359 & 0.361 & 0.364 \\
\hline & $\chi^{2}$ & 0.156 & 0.157 & 0.159 \\
\hline \multirow{6}{*}{ Langmuir } & $\mathrm{Q}^{\mathrm{o}}\left(\mathrm{mg} \mathrm{g}^{-1}\right)$ & 4.432 & 4.438 & 4.441 \\
\hline & $\mathrm{b}(\mathrm{L} / \mathrm{g})$ & 1.023 & 1.027 & 1.033 \\
\hline & $\mathrm{R}_{\mathrm{L}}$ & 3.013 & 3.017 & 3.022 \\
\hline & $\mathrm{r}$ & 0.988 & 0.991 & 0.994 \\
\hline & $\mathrm{sd}$ & 0.975 & 0.979 & 0.983 \\
\hline & $\chi^{2}$ & 0.468 & 0.476 & 0.781 \\
\hline \multirow{6}{*}{$\begin{array}{c}\text { Dubinin - } \\
\text { Radushkevich }\end{array}$} & $\mathrm{k}_{\mathrm{DR}}\left(\mathrm{mol}^{2} \mathrm{~J}^{-2}\right)$ & $6.62 \mathrm{E}-02$ & $6.71 \mathrm{E}-02$ & $6.76 \mathrm{E}-02$ \\
\hline & $\mathrm{X}_{\mathrm{m}}\left(\mathrm{mg} \mathrm{g}^{-1}\right)$ & 4.255 & 4.259 & 4.265 \\
\hline & $\mathrm{E}\left(\mathrm{kJ} \mathrm{mol}^{-1}\right)$ & 9.898 & 9.909 & 9.916 \\
\hline & $\mathrm{r}$ & 0.953 & 0.956 & 0.959 \\
\hline & $\mathrm{sd}$ & 0.968 & 0.972 & 0.975 \\
\hline & $\chi^{2}$ & 0.692 & 0.696 & 0.702 \\
\hline \multirow{5}{*}{ Temkin } & $\mathrm{K}_{\mathrm{T}}(\mathrm{L} / \mathrm{g})$ & 4.285 & 4.291 & 4.296 \\
\hline & $\mathrm{B}_{1}$ & 2.554 & 2.559 & 2.562 \\
\hline & $\mathrm{r}$ & 0.974 & 0.979 & 0.981 \\
\hline & $\mathrm{sd}$ & 0.625 & 0.635 & 0.656 \\
\hline & $\chi^{2}$ & 0.258 & 0.264 & 0.268 \\
\hline \multirow{3}{*}{$\begin{array}{c}\text { Thermodynamic } \\
\text { parameters }\end{array}$} & $\Delta \mathrm{G}^{\mathrm{o}}(\mathrm{kJ} / \mathrm{mol})$ & -2.73 & -2.78 & -2.83 \\
\hline & $\Delta \mathrm{H}^{\mathrm{o}}(\mathrm{kJ} / \mathrm{mol})$ & & 2.24 & \\
\hline & $\Delta \mathrm{S}^{\mathrm{o}}(\mathrm{J} / \mathrm{mol} / \mathrm{K})$ & & 0.26 & \\
\hline
\end{tabular}




\subsection{Kinetics studies}

To identify the order of fluoride adsorption onto AGO@Alg spheres by the kinetic experimental data was concluded with facilitate of reaction-based models such as pseudo-firstorder [58] and pseudo-second-order [59] and diffusion-based models such as particle[ 60] and intraparticle diffusion [61] model which experimental data are portrayed in Table 2. The vital parameters of kinetic models towards defluoridation by AGO@Alg hybrid spheres viz., kad, k, r, $\mathrm{q}_{\mathrm{e}}, \mathrm{h}$ and $\mathrm{r}$ were given in Table 2. Hence, it was noted from the attained parameters of pseudosecond-order that the values of $\mathrm{q}_{\mathrm{e}}$ increasing with increase in temperature than pseudo-first-order denotes the promising of AGO@Alg hybrid spheres in the miscellaneous temperatures viz., 303, 313 and $323 \mathrm{~K}$. Hence, the kinetics of pseudo-second-order model was attained the uppermost r values and smallest sd values which denotes pseudo-second-order model more pertinent models towards defluoridation by AGO@Alg hybrid spheres. 
Table 2. Kinetic studies of AGO@Alg hybrid spheres for fluoride adsorption.

\begin{tabular}{|c|c|c|c|c|c|c|c|c|c|c|c|c|c|}
\hline \multirow{2}{*}{$\begin{array}{l}\text { Kinetic } \\
\text { models }\end{array}$} & \multirow{2}{*}{ Parameters } & \multicolumn{4}{|c|}{$303 \mathrm{~K}$} & \multicolumn{4}{|c|}{$313 \mathrm{~K}$} & \multicolumn{4}{|c|}{$323 \mathrm{~K}$} \\
\hline & & $\begin{array}{c}8 \\
\mathrm{mg} / \mathrm{L}\end{array}$ & $\begin{array}{c}10 \\
\mathrm{mg} / \mathrm{L}\end{array}$ & $\begin{array}{c}12 \\
\mathrm{mg} / \mathrm{L}\end{array}$ & $\begin{array}{c}14 \\
\mathrm{mg} / \mathrm{L}\end{array}$ & $\begin{array}{c}8 \\
\mathrm{mg} / \mathrm{L}\end{array}$ & $\begin{array}{c}10 \\
\mathrm{mg} / \mathrm{L}\end{array}$ & $\begin{array}{c}12 \\
\mathrm{mg} / \mathrm{L}\end{array}$ & $\begin{array}{c}14 \\
\mathrm{mg} / \mathrm{L}\end{array}$ & $\begin{array}{c}8 \\
\mathrm{mg} / \mathrm{L}\end{array}$ & $\begin{array}{c}10 \\
\mathrm{mg} / \mathrm{L}\end{array}$ & $\begin{array}{c}12 \\
\mathrm{mg} / \mathrm{L}\end{array}$ & $\begin{array}{c}14 \\
\mathrm{mg} / \mathrm{L}\end{array}$ \\
\hline \multirow{3}{*}{$\begin{array}{l}\text { Pseudo- } \\
\text { first-order }\end{array}$} & $\mathrm{k}_{\mathrm{ad}}\left(\min ^{-1}\right)$ & 0.204 & 0.209 & 0.214 & 0.219 & 0.207 & 0.212 & 0.217 & 0.226 & 0.211 & 0.215 & 0.221 & 0.233 \\
\hline & $\mathrm{r}$ & 0.884 & 0.889 & 0.896 & 0.902 & 0.888 & 0.892 & 0.899 & 0.906 & 0.891 & 0.895 & 0.902 & 0.910 \\
\hline & sd & 0.366 & 0.372 & 0.377 & 0.384 & 0.370 & 0.376 & 0.382 & 0.388 & 0.374 & 0.381 & 0.386 & 0.392 \\
\hline \multirow{5}{*}{$\begin{array}{l}\text { Pseudo- } \\
\text { second- } \\
\text { order }\end{array}$} & $\mathrm{q}_{\mathrm{e}}(\mathrm{mg} / \mathrm{g})$ & 4.644 & 4.651 & 4.657 & 4.663 & 4.648 & 4.654 & 4.661 & 4.670 & 4.652 & 4.660 & 4.666 & 4.674 \\
\hline & $\mathrm{k}\left(\mathrm{g} / \mathrm{mg} \min ^{-1}\right)$ & 0.112 & 0.119 & 0.126 & 0.132 & 0.116 & 0.124 & 0.131 & 0.139 & 0.122 & 0.129 & 0.136 & 0.145 \\
\hline & $\mathrm{h}\left(\mathrm{mg} / \mathrm{g} \min ^{-1}\right)$ & 4.034 & 4.040 & 4.047 & 4.054 & 4.037 & 4.044 & 4.052 & 4.061 & 4.043 & 4.050 & 4.058 & 4.066 \\
\hline & $\mathrm{r}$ & 0.991 & 0.993 & 0.996 & 0.998 & 0.992 & 0.994 & 0.997 & 0.999 & 0.993 & 0.995 & 0.998 & 0.999 \\
\hline & sd & 0.098 & 0.108 & 0.115 & 0.127 & 0.103 & 0.113 & 0.122 & 0.134 & 0.111 & 0.119 & 0.129 & 0.140 \\
\hline \multirow{3}{*}{$\begin{array}{l}\text { Particle } \\
\text { diffusion }\end{array}$} & $\mathrm{k}_{\mathrm{p}}\left(\min ^{-1}\right)$ & 1.108 & 1.115 & 1.123 & 1.132 & 1.113 & 1.120 & 1.129 & 1.138 & 1.117 & 1.126 & 1.135 & 1.144 \\
\hline & $\mathrm{r}$ & 0.844 & 0.850 & 0.856 & 0.864 & 0.849 & 0.854 & 0.861 & 0.870 & 0.852 & 0.858 & 0.864 & 0.876 \\
\hline & sd & 0.422 & 0.429 & 0.436 & 0.443 & 0.427 & 0.433 & 0.441 & 0.449 & 0.430 & 0.438 & 0.445 & 0.454 \\
\hline \multirow{3}{*}{$\begin{array}{l}\text { Intra } \\
\text { particle } \\
\text { diffusion }\end{array}$} & $\mathrm{k}_{\mathrm{i}}\left(\mathrm{mg} / \mathrm{g} \min ^{0.5}\right)$ & 2.547 & 2.554 & 2.562 & 2.570 & 2.552 & 2.560 & 2.567 & 2.576 & 2.556 & 2.564 & 2.572 & 2.581 \\
\hline & $\mathrm{r}$ & 0.955 & 0.961 & 0.966 & 0.971 & 0.959 & 0.963 & 0.968 & 0.975 & 0.961 & 0.966 & 0.973 & 0.981 \\
\hline & sd & 0.158 & 0.167 & 0.174 & 0.182 & 0.161 & 0.170 & 0.179 & 0.187 & 0.166 & 0.172 & 0.183 & 0.192 \\
\hline
\end{tabular}


Fluoride released within the interior pore area of AGO@Alg hybrid spheres through the fluoride adsorptions method. The rate of diffusion improved when fluoride ion come into within owing to diffusion rate was improved. The particle and intraparticle diffusion models of straight linear plots of AGO@Alg hybrid spheres to fluoride adsorption were plotted by $\ln \left(1-\mathrm{C}_{\mathrm{t}} / \mathrm{C}_{\mathrm{e}}\right)$ vs $\mathrm{t}$ and $\mathrm{q}_{\mathrm{t}} \mathrm{vs} \mathrm{t}^{0.5}$ respectively. It was chiefly completed that from the attained parameter values of intraparticle diffusion model such as higher $\mathrm{r}$ and lower sd values exhibits their prospective for defluoridation by AGO@Alg hybrid spheres.

\subsection{Defluoridation mechanism of AGO@Alg spheres}

The plausible mechanism of AGO@Alg spheres towards fluoride adsorption was mainly controlled by electrostatic attraction (c.f. Figure 7). The prepared AGO@Alg hybrid spheres have the active functional groups like amine and hydroxyl groups. The aminated GO contain s lot of active amine groups and Alg possess reactive functional groups like - $\mathrm{OH}$ groups. In general, the protonated groups have high tendency to interact with fluoride ion through electrostatic interaction. At acidic $\mathrm{pH}$ condition, AGO@Alg hybrid spheres fully protonated and the protonated AGO@Alg hybrid spheres interact with fluoride ion through electrostatic interaction mechanism.
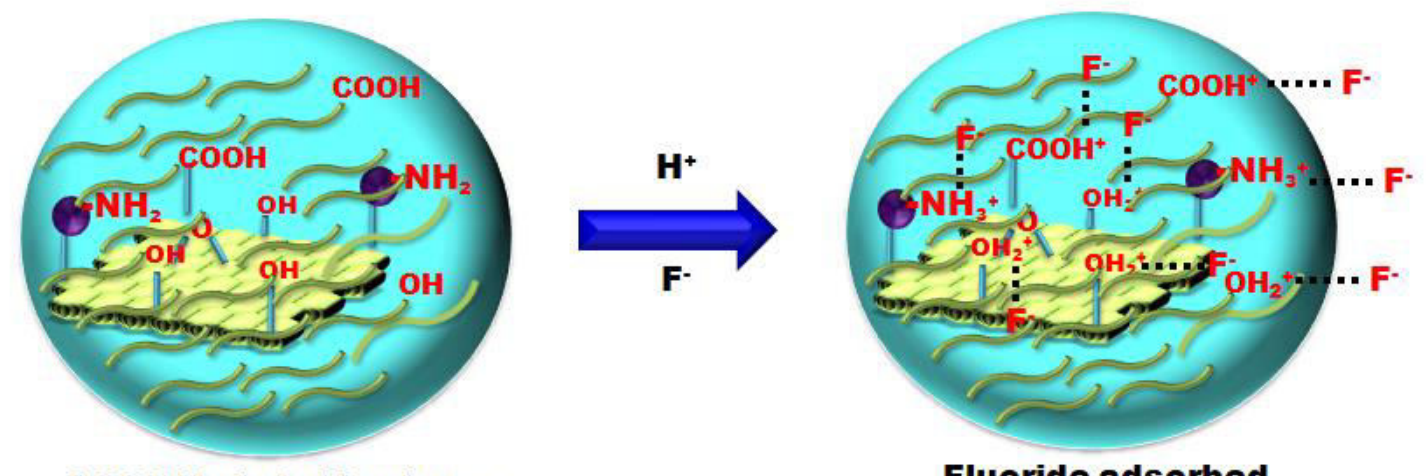

AGO@Alg hybrid spheres

Fluoride adsorbed AGO@Alg hybrid spheres

\section{Electrostatic attraction}

Figure 7. The defluoridation mechanism of AGO@Alg hybrid spheres. 


\subsection{Field water analysis}

To check the AGO@Alg hybrid spheres aptness at field trail, the fluoride containing field water sample was collected from a village in Dindigul district, Tamilnadu. The fluoride concentration was found in the field water sample as $3.05 \mathrm{mg} / \mathrm{L}$. The AGO@ Alg hybrid spheres acquire the high affinity towards defluoridation as their equilibrium concentration after the treatment was identified to be under WHO tolerance level (c.f. Table 3). However, the other water quality deciding parameters such as total hardness, dissolved oxygen, total dissolved solids and chloride of the real water sample was too proscribed by AGO@Alg hybrid spheres confirms its field aptness.

Table 3. Field aptness of AGO@Alg hybrid spheres.

\begin{tabular}{lcc}
\hline Water quality parameters & Before treatment & After treatment \\
\hline Initial F concentration $\left(\mathrm{mg} \mathrm{L}^{-1}\right)$ & 3.05 & 1.20 \\
$\mathrm{pH}$ & 5.99 & 7.02 \\
Dissolved oxygen $\left(\mathrm{mg} \mathrm{L}^{-1}\right)$ & 5.98 & 6.56 \\
$\mathrm{Cl}^{-}\left(\mathrm{mg} \mathrm{L}^{-1}\right)$ & 415 & 2112 \\
Total hardness $\left(\mathrm{mg} \mathrm{L}^{-1}\right)$ & 591 & 420 \\
Total dissolved solids $\left(\mathrm{mg} \mathrm{L}^{-1}\right)$ & 860 & 431 \\
\hline
\end{tabular}

\subsection{Reusability studies of AGO@Alg spheres}

To check the recyclability and cost effectiveness of AGO@Alg hybrid spheres was conducted by regeneration studies. Herein, $\mathrm{NaOH}(0.1 \mathrm{M})$ was utilized as eluent for adsorptiondesorption cycle of AGO@Alg hybrid spheres. Hence, $0.1 \mathrm{~g}$ of fluoride treated AGO@Alg spheres were entirely immersed into 0.1 mole of $\mathrm{NaOH}$. The observed result indicates addition of $\mathrm{NaOH}$ in all the cycles, the fluoride removal efficiency was diminished gradually which is 
depicted in Figure 8. The possible reason is $\mathrm{OH}^{-}$ion in $\mathrm{NaOH}$ exchange fluoride ion by ionexchange due to this removal efficiency of AGO@Alg hybrid spheres was gradually diminished in each and every cycle. Moreover, practically removal efficiency of $80 \%$ was attained upto 6 cycles. Henceforth, the recyclability of AGO@Alg hybrid spheres was chosen upto 6 cycles.

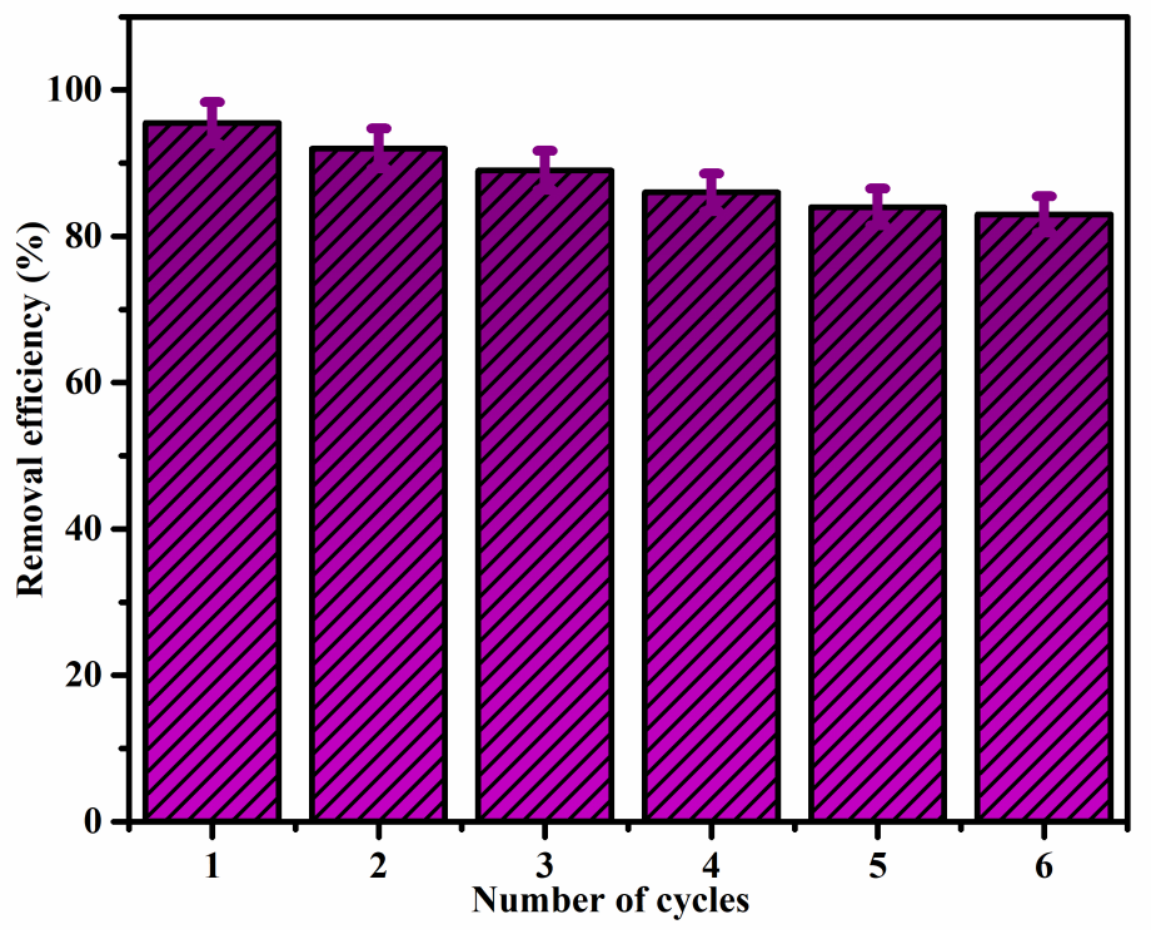

Figure 8. Regeneration studies of AGO@Alg hybrid spheres.

\section{Conclusions}

The prepared AGO@Alg hybrid spheres exhibit the enhanced DC of $4440 \mathrm{mgF}^{-} \mathrm{kg}^{-1}$ within 30 min of optimum time. The adsorbate $\mathrm{pH}$ was mostly changed the nature of AGO@Alg hybrid spheres surface which influence DC. The $\mathrm{HCO}_{3}{ }^{-}$ion present in ordinary water was noticeably influences during defluoridation. The attribute of AGO@Alg hybrid spheres were demonstrated with XPS, TGA, FTIR and SEM analysis. The kinetics studies of AGO@Alg spheres were achieved wherein pseudo-second-order and intraparticle diffusion model were well matched for fluoride adsorption. Moreover, the Langmuir adsorption isotherm of AGO@Alg hybrid spheres was apt for fluoride removal. The defluoridation spontaneity and endothermic 
nature was stated by the thermodynamic studies. The defluoridation mechanism of AGO@Alg spheres was mostly retained by the electrostatic attraction. The recyclability of AGO@Alg hybrid spheres was reached upto 6 cycles. Besides, AGO@Alg spheres were applied with the field fluoride water sample and results show that the prepared AGO@Alg hybrid spheres manages all the water quality parameters which indicates their suitability at field level.

\section{Acknowledgements}

The authors thank the Council of Scientific and Industrial Research (CSIR) (F.No. 01(2965)/19/EMR-II), New Delhi, India for the financial support to carry out this research work.

\section{References}

1. A. Jeyaseelan, and N.Viswanathan, J. Chem. Eng. Data 65 (2020) 5328-5340.

2. D. Huang, J.Yang, X. Wei, J. Qin, S. Ou, Z. Zhang, Y. Zou, Environ. Pollut. 222 (2017) 118-125.

3. C. Li, N. Chen, Y. Zhao, R. Li, C. Feng, Chemosphere 163 (2016) 81-89.

4. J. Zhang, N. Chen, Z. Tang, Y. Yu, Q. Hu, C. Feng, Phys. Chem. Chem. Phys. 17 (2015) 12041-12050.

5. A. Jeyaseelan, M. Naushad, N. Viswanathan, J. Chem. Eng. Data 65 (2020) 2990-3001.

6. M.V.N. Samrat, K.K. Rao, A.K. SenGupta, J. Riotte, J.R. Mudakavi, J. Water Process. Eng. 23 (2018) 327-337.

7. A. Azari, R.R. Kalantary, G. Ghanizadeh, B. Kakavandi, M. Farzadkia, E. Ahmadi, RSC Adv. 5 (2015) 87377-87391.

8. A. Jeyaseelan, M. Naushad, T. Ahamad, N. Viswanathan, J. Environ. Chem. Eng. (2020)104563.

9. S.M. Prabhu, S. Meenakshi, J. Water Process. Eng. 2 (2014) 96-104.

10. S. George, P. Pandit, A.B. Gupta, Water Res. 44 (2010) 3055-3064. 
11. J.A. Arcibar-Orozco, A.I. Flores-Rojas, J.R. Rangel-Mendez, P.E. Díaz-Flores, Environ. Technol. 41 (2020) 1554-1567.

12. C.E. Choong, M. Kim, S. Yoon, G. Lee, C.M. Park, J. Taiwan Inst. Chem. Eng.93 (2018) 306-314.

13. M.K. Uddin, S.S. Ahmed, M. Naushad, Desalin. Water Treat.145 (2019) 232-248.

14. S. De Gisi, G. Lofrano, M. Grassi, M. Notarnicola, Sustain. Mater. Technol. 9 (2016) 1040.

15. E.F. Sheka, Y.A. Golubev, N.A. Popova, Nanomaterials, 10 (2020) 2021.

16. J. Klimeš, A. Michaelides, J. Chem. Phys.137 (2012) 120901.

17. H. Chang, H. Wu, Adv. Funct. Mater. 23(2013) 1984-1997.

18. F. Chen, Q. Qing, J. Xia, N. Tao, Chem. Asian J. 5 (2010) 2144-2153.

19. Y. Song, H. Wang, W. Liu, H.Wang, L. Yan, J. Alloys Compd.780 (2019) 55-64.

20. N. Ashraf, A. Majid, M. Rafique, M.B. Tahir, Chin. J. Phys. (2020).

21. S. Stankovich, D.A. Dikin, R.D. Piner, K.A. Kohlhaas, A. Kleinhammes, Y. Jia, Y. Wu, S.T. Nguyen, R.S. Ruoff, Carbon 45 (2007) 1558-1565.

22. P. Steurer, R.Wissert, R. Thomann, R. Mülhaupt, Macromol. Rapid Commun. 30 (2009) 316-327.

23. M.J. McAllister, J.L. Li, D.H. Adamson, H.C. Schniepp, A.A. Abdala, J. Liu, M. Herrera-Alonso, D.L. Milius, R. Car, R.K. Prud'homme, I.A. Aksay, Chem. Mater. 19 (2007) 4396-4404.

24. L. Dong, J. Yang, M. Chhowalla, K.P. Loh, Chem. Soc. Rev. 46 (2017) 7306-7316.

25. N. Xu, S. Li, W. Li, Z. Liu, Chem. Select 5 (2020) 1818-1828.

26. M.R. Awual, M.M. Hasan, A. Islam, M.M. Rahman, A.M. Asiri, M.A. Khaleque, M.C. Sheikh, J. Clean. Prod. 228 (2019) 778-785. 
27. J. Li, X. Wang, G. Zhao, C. Chen, Z. Chai, A. Alsaedi, T. Hayat, X. Wang, Chem. Soc. Rev. 47 (2018) 2322-2356.

28. M. Manzano, V. Aina, C.O. Arean, F. Balas, V. Cauda, M. Colilla, M.R. Delgado, M. Vallet-Regi, Chem. Eng. J. 137 (2008) 30-37.

29. I. Aswin Kumar, C. Jeyaprabha, N. Viswanathan, J. Environ. Chem. Eng. 8 (2020) 103894.

30. M. Bilal, T. Rasheed, F. Nabeel, H.M. Iqbal, In Biofibers and Biopolymers for Biocomposites, Springer, Cham. (2020) 135-157.

31. G.E. Luckachan, C.K.S. Pillai, J. Polym. Environ.19 (2011) 637-676.

32. N.M. Mahmoodi, J.Taiwan Inst. Chem. Eng. 44 (2013) 322-330.

33. K. Pandi, N. Viswanathan, RSC Adv. 6 (2016) 75905-75915.

34. B.S. Ge, T. Wang, H.X. Sun, W. Gao, H.R. Zhao, Polym. Adv. Technol. 29 (2018) 13341343.

35. K. Pandi, N. Viswanathan, J. Appl. Polym. Sci. 132 (2015).

36. J.E. Harwood, Water Res. 3 (1969) 273-280.

37. J.B. Wu, M.L. Lin, X. Cong, H.N. Liu, P.H.Tan, Chem. Soc. Rev. 47 (2018) 1822-1873.

38. B. Wang, B. Luo, M. Liang, A. Wang, J. Wang, Y. Fang, Y. Chang, L. Zhi, Nanoscale 3 (2011) 5059-5066.

39. S. Babu Maddinedi, B.K. Mandal, S.H. Patil, V.V. Andhalkar, S. Ranjan, N. Dasgupta, J. Photoch. Photobio. B.166 (2017) 252-258.

40. J.A. Luceño-Sánchez, G. Maties, C. Gonzalez-Arellano, A.M. Diez-Pascual, Nanomaterials 8 (2018) 870 .

41. S.K. Papageorgiou, E.P. Kouvelos, E.P. Favvas, A.A. Sapalidis, G.E. Romanos, F.K. Katsaros, Carbohydr. Res. 345 (2010) 469-473. 
42. Z. Yi, L. Huajie, L. Mingchun, X. Meihua, J. Mol. Struct. 1209 (2020) 127973.

43. M. Sarvestani, R. Azadi, Appl. Organomet. Chem. 32 (2018) e3906.

44. V. Gopalakannan, N.Viswanathan, Inter. J.Biol. Macromol. 72 (2015) 862-867.

45. A. Navaee, A. Salimi, RSC Adv. 5 (2015) 59874-59880.

46. D. Hulicova-Jurcakova, M. Kodama, S. Shiraishi, H. Hatori, Z.H. Zhu, G.Q. Lu, Adv. Funct. Mater. 19 (2009) 1800-1809.

47. L.F. Lai, G.M. Huang, X.F. Wang, J. Weng, Carbon 48 (2010) 3145-3156.

48. C. Struzzi, M. Scardamaglia, N. Reckinger, H. Sezen, M. Amati, L. Gregoratti, J.F. Colomer, C. Ewels, R. Snyders, C. Bittencourt, Phys. Chem. Chem. Phys. 19 (2017) 3141831428.

49. N. Viswanathan, I. Aswin Kumar, S. Meenakshi, Inter. J.Biol. Macromol.133 (2019) 811-816.

50. A. Jeyaseelan, M.D. Albaqami, N. Viswanathan, J. Environ. Chem. Eng. 9 (2020)104995.

51. I. Langmuir, J. Am. Chem. Soc. 38 (1916) 2221-2295.

52. H.M.F. Freundlich, Z. Phys. Chem. 57 (1906) 385-470.

53. M.M. Dubinin, E.D. Zaverina, L.V. Radushkevich, J. Phys. Chem 21 (1947) 1351-1362.

54. A. Jeyaseelan, N. Viswanathan, J. Mol. Liq. 326 (2021) 115163.

55. A. Jeyaseelan, M. Naushad, T. Ahamad, N. Viswanathan, Environ. Sci. Water Res. Technol. 7 (2021) 384-395.

56. A.A. Khan, R.P. Singh, Colloids Surf. 24 (1987) 33-42.

57. H.N. Tran, S.J. You, H.P. Chao, J. Environ. Chem. Eng. 4 (2016) 2671-2682.

58. Y.S. Ho, G. McKay, 34 (1999) 451-465.

59. Y.C. Wong, Y.S. Szeto, J. Appl. Polym. Sci. 92 (2004) 1633-1645. 
60. H.A. Kramers, 7 (1940) 284-304.

61. G.H. Graaf, H. Scholtens, E.J. Stamhuis, A.A.C.M., Chem. Eng. Sci. 45 (1990) 773-783. 